\title{
ESTIMATION AND COMPARISON OF VITAMIN D BINDING PROTEIN CONCENTRATE IN GINGIVAL CREVICULAR FLUID AND SERUM OF SUBJECTS WITH CHRONIC PERIODONTITIS
}

\author{
Sharmila Thangavel*, MDS., Prabhuji Munivenkatappa Lakshmaiah Venkatesh,MDS \& Karthikeyan Bangalore \\ Varadhan, MDS ;
}

Department of Periodontology and Implantology,Krishnadevaraya College of Dental Sciencesand Hospital, Krishnadevarayanagar,Hunsmaranahalli, International Airport Road,Bengaluru- 562157, Karnataka, India

\begin{abstract}
Objectives: Vitamin D-binding protein (DBP) has a potent effect on immunity and inflammation. To date, not much is known regarding the significance of DBP in relationship between chronic periodontitis with systemic conditions and there is only a limited evidence that exist. Hence, the aim of current study, which is first of its kind, was carried out to analyze and correlate DBP levels in Crevicular fluid (GCF) and Serum, in periodontitis and consequently, after periodontal therapy. Material and Methods: GCF and Serum was sampled from each patient, and levels of DBP were analyzed by Immuno Assay (ELISA). Outcomes were statistically analyzed. Results: The increase of DBP concentration in GCF and serum in chronic periodontitis and decline in its value following nonsurgical treatment of chronic periodontitis proves there is a positive correlation of DBP with the extent of periodontal inflammation.Conclusion: To conclude, DBP levels in GCF are upregulated in periodontitis and concomitantly there was a rise in DBP levels systemically. This suggests, that DBP is involved in the pathogenesis of periodontitis and highlights our preliminary evidence towards the possible role of DBP in the link between periodontitis and systemic continuum.
\end{abstract}

Keywords: Vitamin D-binding protein (DBP); Periodontitis; Gingival Crevicular fluid; Serum. 


\section{INTRODUCTION}

Periodontitis is a chronic localized infection of the oral cavity that induces inflammatory immune response both locally and systemically.(1) Although microorganisms are considered to be the etiologic agent that causes this inflammatory response, it is the mediators of inflammation which plays a crucial role in the destruction of periodontal support .(2) Amongst them Vitamin $D$ binding protein (DBP) a monomeric, multifunctional glycoprotein which has defensive role independent of vitamin $D$ carriage, such as coactivating macrophages, increasing the chemotaxis of C5-derived peptides and associated along the cellular surface of neutrophils monocytes, B cells and T cells. $(3,4)$

DBP is an acute-phase reactant synthesized in parenchymal cells of hepatic, in an integral manner (5) and plasma concentration in healthy subject is 300-600 $\mu \mathrm{g} / \mathrm{ml}$, except during pregnancy and estrogen therapy state when a substantial increase is seen by the liver. In addition, it scavenges actins released from necrotic cells, plays a part in bone modulation and bacterial agglutination .(4)

Overall, it is noteworthy observation that DBP has a significant impact on systemic health. It is believed that variations of plasma DBP levels are valuable markers for some diseases, like tuberculosis, (6)Type 1 diabetes, (7) sepsis, (8)cystic fibrosis (3) and off lately STelevation myocardial infarction, (9)asthma,
COPD, cancer (10) and dementia. (11) In terms of cardiovascular disease, high expression of DBP protein has been found in fresh thrombotic plaques and in the serum of patients with ST elevated myocardial infarction. (9)

With regard to periodontal health and disease, DBP might exert a similar role in maintaining periodontal health. It is considered periodontal tissues might be another source of GCF DBP other than serum .(12) Study by Zhang, Meng (12) found that DBP is found in higher concentration in GCF of healthy subjects compared to subjects with Aggressive Periodontitis (GAgP). It is evident that as periodontal disease progresses there is a decline in the Crevicular Fluid DBP levels and concomitant increase in saliva $(4,13)$, and plasma levels $(12,14)$ in GAgP. Further it was noticed that, there was simultaneous increase in DBP levels as the PMN raises in plasma. Therefore, a strong clinical rational exists for DBP levels and progression of periodontitis.

Despites this, there is little known regarding the association DBP with chronic periodontitis and systemic health. Therefore, the present study which is first of its kind, is designed to explore the DBP levels in the GCF and serum in periodontal health and disease and to evaluate if periodontal therapy has any influence on serum and GCF DBP levels.

\section{MATERIALS AND METHODS}

Study subjects: Comprised 40 sex matched individuals, around the age group of 30-39, who were willing to contribute and had given written informed 
consent. Participating subjects were referred from outpatient section, Periodontics Department KCDS, Bangalore, since January 2016 until March 2016. The decorum of the study was permitted by Ethical Board allied to the Rajiv Gandhi University, Bengaluru, India. [KCDS 02_DO12_54544]

Inclusion /exclusion criteria: A full mouth periodontal examination, which included Gingival Index (GI), Probing Pocket Depth (PPD), Relative Attachment Loss (RAL), Plaque Index (PI) and orthopantomograph (OPG) was performed for all individuals included in the study. Based on the GI, PPD and RAL, subjects were categorized into two groups. Group 1(Periodontal health$\mathrm{PH})$ comprised of 20 subjects with healthy periodontium, $\mathrm{PPD} \leq 3 \mathrm{~mm}, \mathrm{Gl} \leq 1$ and $\mathrm{RAL}=$ $0 \mathrm{~mm}$. Group 2a (Chronic periodontitis $\mathrm{CP}$ ) involved 20 individuals who had signs of clinical inflammation PPD $\geq 5 \mathrm{~mm}, \mathrm{Gl} \geq$ 2 , and $R A L \geq 8 \mathrm{~mm}$ (in two noncontiguous sites). Patients in Group 2a were treated with nonsurgical therapy (i.e. SRP) formed Group2b (After therapy chronic periodontitis -ATCP) in whom Crevicular fluid and serum was collected from the original sites 3 months after treatment (Figure 1). The diagnostic criteria for $\mathrm{CP}$ is the classification anticipated at the Workshop intended for the Classification of Periodontal Diseases and Conditions in 1999.(15)

Exclusion criteria included: Systemic diseases that could influence the periodontal disease progression for instance multiple sclerosis, viral, fungal and bacterial infections, diabetes mellitus, inflammatory bowel disease, rheumatoid arthritis, cardiorespiratory disease, pregnancy, lactation, history of smoking around previous 5 years and current smoking, any periapical pathology, any form of periodontal procedures or use of any antibiotics or nonsteroidal antiinflammatory drugs (NSAIDS) within the duration of 6 months from baseline examination, aggressive periodontitis subjects on Vitamin D supplements, and recent orthodontic treatment.

Protocol for Non-surgical periodontal treatment: All periodontitis patient were given plaque control instructions. Periodontitis patients of group $2 a$ underwent comprehensive scaling and root planning procedure, in two sessions within seven days by means of hand and ultrasonic instrumentation under the influence of local anesthesia $12 \%$ lignocaine hydrochloride with 1:2,00,000 adrenaline) with session not prolonging beyond an hour. Participating subjects were placed on a 4 week maintenance protocol to make certain that there is effective plaque removal and inflammation control of gingival tissues. Patient were advised for a monthly visit, Oral hygiene instructions (OHI) were reinforced and coronal polishing was provided. Periodontally healthy individuals (PH group) did not under go any periodontal therapy. Sample collection for DBP levels in Crevicular fluid and serum alongside clinical assessment of Gl, PPD, and RAL were performed at different time frame (baseline and 3 months after therapy). 


\section{EXPERIMENTAL DESIGN AND TREATMENT PROTOCOLS}

Clinical measurements: Patient periodontal status was recorded my quantifying PPD, RAL, and Gl. Orthopantomograph was used to record the level of bone loss. Periodontal probe UNC-15 (Hu-Friedy Manufacturing Co., Chicago, IL, USA) was used for all clinical measurements which were recorded on all the six sites of the tooth by the first examiner (ST).

\section{Site Selection and Collection of GCF:}

All subjects were assessed clinically for their periodontal status, under illumination using a sterile graduated periodontal probe UNC-15 and mouth mirror. The one site in each subject that with the highest level of RAL and radiographic validation of bone loss in patients with CP group and ATCP group was carefully chosen for Crevicular fluid and serum collection. Periodontitis being a site-specific disease, only one site per patient was selected to avoid pooling of samples from multiple area, the area was dried with blast of air, and supragingival plaque was removed without disturbing the marginal gingiva.

At area of sample collection, isolation with cotton rolls was done to prevent saliva contamination. With standard paper strips Periopaper; Oraflow Inc., Smithtown, NY, USA, sample of Crevicular fluid was collected inserting to a depth of approximately $2 \mathrm{~mm}$, into the sulcus/ pocket for $30 \mathrm{~s}$. Strips were discarded if contaminated with blood. Collected Crevicular fluid volume was quantified using a calibrated appliance
(Periotron 8000; Proflow Inc., Amityville, NY, USA) and these interpretations was changed to an original volume $(\mu \mathrm{L})$ by orientation to a standard curve generated using the Periotron readings of the fluid volume $(\mu \mathrm{L})$ in the Periopaper strips.

Following quantitative analysis, the strips were transferred to Eppendorf tubes containing $100 \mu \mathrm{L}$ of buffered phosphate saline solution. To elute GCF from paper strips, the aliquots were centrifuged at 3000 rpm for 15 minutes, and then the strips were removed and the collected samples were refrigerated at $-80^{\circ} \mathrm{C}$ until the assay was performed.

\section{Procedure for serum collection}

A 20 gauge needle and $2 \mathrm{ml}$ syringe was used to collect $2 \mathrm{ml}$ of blood from the antecubital fossa which was immediately transferred to the red topped serum separator blood collection tube (SST). The blood samples were allowed to clot at normal room temperature for a minimum of 30 minutes, and then centrifuged at $3000 \mathrm{rpm}$ for 15 minutes to separate serum and transferred to an Eppendorf tube which was stored at $-80^{\circ} \mathrm{C}$ until the time of assay

Samples were then assayed for DBP levels using Human Vitamin D-binding protein (DBP) ELISA, obtained from QAYEE$\mathrm{BIO}{ }^{\circledR}$, (Human Vitamin D-Binding Protein (Item No: QY-E01061, Specifications: 96T). The above presented kit reported an assay sensitivity of $<120 \mathrm{ng} / \mathrm{ml}$. In connection to specificity of the kit, the manufacturer testified no significant cross reactivity. Results of the samples were reported in nanogram per milliliter (ng/ml). 
Sites with a probing depth of $\geq 5 \mathrm{~mm}$ showed a difference in DBP ,3 months after complete scaling and root planning which was the primary outcome variable. The secondary outcome variable considered were the changes in full mouth $\mathrm{Gl}$ score in sites with a initial probing depth of $5-8 \mathrm{~mm}$. Microsoft excel was used to enter all the data including clinical and biochemical measurements which were later analyzed using SPSS software(Statistical Package for Social Science, Ver.10.0.5). Normality assumption of the data was analyzed using Shapiro-Wilks test. Any statistical difference between the parameters in the groups were determined using paired sample ' $t$ ' test. Pearson's correlation ( $r$ ) technique was used to determine the strength of linear relationship between two variables. A $p$ - value was set at $95 \%$ level of significance.

\section{RESULTS}

All the samples in each group were tested positive for DBP examination. Table 1 shows the demographic physiognomies and full-mouth clinical parameters of three groups.

Normality assumptions were tested for the mean values of PI, GI, PPD, and RAL of $\mathrm{PH}, \mathrm{CP}$ group and ATCP group. The scores were the highest for CP group (2.5, $82 \%, 8.5 \mathrm{~mm}$, and $11.2 \mathrm{~mm}$ respectively). The lowest score was observed in $\mathrm{PH}$ group for PI and $\mathrm{GI}(0.3,14.9 \%)$. Values of ATCP group for PI, GI, PPD, and RAL scores (1.2, $19.1 \%, 5.1 \mathrm{~mm}$ and $7.71 \mathrm{~mm}$ respectively) were lesser than CP group but higher than $\mathrm{PH}$ group.
To test the hypothesis of equality of means for DBP concentrations in GCF and serum in-between CP group and ATCP group Parametric paired sample ' $t$ ' test was carried out (Intragroup comparison), the results for which are tabulated in Table 2. (Figure 2). The $p$-value for inter-group comparisons for all three groups is $<0.05$, which infers the rejection of null hypothesis. On further analysis of the three groups, statistical significance was noted between $\mathrm{PH}$ group vs $\mathrm{CP}$ group and $\mathrm{CP}$ group vs ATCP group, with $P$ value $<0.05$. This indicates that with increasing inflammation, the GCF DBP concentrations increase and they decrease after NSPT.

Pearson correlation was done to check for any association between the GCF and serum DBP concentrate and the clinical findings in $\mathrm{PH}$ group, CP group and ATCP group. Table 3 shows the association amongst GCF and Serum in DBP with clinical findings from $\mathrm{CP}$ and ATCP.

To summarize, GCF and serum samples for all the subjects demonstrated the presence of DBP. The quantified results confirmed the hypothesis that GCF and serum DBP concentrations rise with increasing grade of inflammation during periodontal diseases and reduce after NSPT.

\section{DISCUSSION}

"DBP is a a2-globulin of plasma protein and is found in blood in ample quantity. DBP have remained associated in the pathology of periodontal infection and systemic condition, further in GAgP there is 
a positive correlation between GCF and Serum level of DBP.(14) However, there are no studies in the literature on the role of DBP in chronic periodontitis and on its association with general health. Hence, the current study was carried out to quantify the DBP concentration in Crevicular fluid and Serum of patient, with periodontitis. Further, to gauge the impact of periodontal therapy on DBP levels locally and systemically.

The present study showed a raise in mean GCF DBP concentration in CP 162.97 $\mathrm{ng} / \mathrm{ml}$ ) when compared to $\mathrm{PH}$ $(8.451 \mathrm{ng} / \mathrm{ml})$. Similarly, serum also showed a same trend where in there was a raise in mean DBP concentration in CP (512.1 $\mathrm{ng} / \mathrm{ml})$ when compared to $\mathrm{PH}(360.2$ $\mathrm{ng} / \mathrm{ml})$.This raise in DBP levels with increasing grade of periodontal inflammation indicates DBP concentration correlates positively with extent of periodontal inflammation.

Results attained in our study are in harmony with the earlier studies done by several authors. Baliban et al , (16) had done a large scale comprehensive proteomic analysis and showed that DBP levels are higher in $\mathrm{CP}$ when compared to $\mathrm{PH}$. Also, in a cross-sectional study by SilvaBoghossian et al,(17) who quantified proteome composition of the GCF in $\mathrm{PH}$ and $\mathrm{CP}$ patients, reported that DBP was found in a substantial greater abundance in periodontal sites when associated to the $\mathrm{PH}$ group. Whole saliva of patient with periodontitis showed higher DBP levels when compared with dentulous or edentulous subjects. (4) However, there is an conflicting study reported in the literature by Zhang et al,(12) who had assessed DBP levels of GAgP in GCF and plasma to controls (healthy)and interpreted that DBP concentration were significantly lower in GCF of GAgP and comparatively was higher in healthy periodontal conditions. The author stated that there is a negative correlation of DBP levels with periodontal inflammation. The reason for this result is unclear, and they assumed that this might be due to absence of active production or a rise in local consumption.(12) The recent study by Li, Zhu et al (18) also have reported DBP levels are higher in healthy periodontal tissues, suggesting it plays an active role in local host defense and hard tissue metabolism.

The raise in GCF DBP levels as noticed in this study may be due to several reasons. First, inflammatory state leading to increased production of DBP as the binding of DBP to the surface of neutrophils (19) and monocytes (20) leads to upregulation .(21) Secondly, DBP isoforms have shown to regulate inflammatory cytokines, which are known to increase DBP mRNA approximately twofold as reported by Guha et al.(5) Thirdly, DBP is a molecule which is known to entail in macrophage activation (22-24) and osteoclast differentiation, $(22,25)$ thereby trafficking more inflammatory cells towards the site of inflammation leading to periodontal destruction. Fourth, DBP spikes complement action by promoting inflammation. Fifth, LPS released from periodontally inflamed sites might activate 
neutrophils and increase DBP binding sites .(26) Current findings could enhance our understanding on mechanism accounting for the association of periodontal inflammation with DBP levels.

Concomitantly, we also observed that there was an increase in DBP levels in the serum with the extent of periodontal inflammation and it may be due to First, release of DBP from periodontal inflamed tissues in to systemic circulation. Second, DBP has been implied as an acute phase reactant, its hepatic production might be upregulated reciprocally by proinflammatory cytokines released from inflamed periodontal tissues .(12) Third, raised PMN (Neutrophils) levels in inflammation further raises DBP levels. In our study, we noticed that there is a rise in serum DBP levels by many fold as the periodontal disease progresses, as it possibly has a direct effect on systemic conditions like cardiovascular $(9,24,27)$ and respiratory diseases $(28,29)$. This implies that DBP has an influence on inflammation and immune function and could act as a bridging link in the pathology of periodontal and systemic continuum.

In addition, we identified that with periodontal treated patients showed a reduction in mean GCF $(62.97 \mathrm{ng} / \mathrm{ml})$ and serum $(512.14 \mathrm{ng} / \mathrm{ml})$ DBP levels to after treatment levels of $(20.97 \mathrm{ng} / \mathrm{ml}$ in GCF, $456.8 \mathrm{ng} / \mathrm{ml}$ in Serum) respectively which were also statistically significant. Further, the decrease in DBP levels showed positive correlation with clinical measures of periodontal disease (GI, PPD, and RAL). This suggests that rendered treatment reduced the microbial inflammatory load and lower thereby by the DBP levels and confirms the relationship between local and serum DBP levels with periodontal inflammation.

Furthermore, in the present study GCF and serum DBP levels were reduced when compared to those stated in other studies. It may be attributed to heterogeneous responses due to differences in human race,(30) difference in the sensitivity of ELISA kit, (12) breakdown of DBP during storage time, short plasma half-life and the bound form of DBP not getting detected by ELISA.

It should be also noted that there were some limitations in our study. First, DBP has variant genotype which could have affected the DBP detection. Second, DBP depends upon the gender (estrogen levels), and the influence of sex on DBP levels could not be quantified in our study as the study was gender matched. Third, the storage time was around six months and there is a possibility that during the storage time, DBP molecule might have developed a stronger bond with other molecule or metabolized due to their short half-life. Fourth, region sampled were just one and might not have represented the status of complete periodontal inflammation of the study subject.

Taken together, within the limits of our study, it can be summarized that, greater the extent of periodontal inflammation, there is a considerable up raise in the quantity of DBP in GCF and serum and the interventional therapy (SRP) reduced the DBP levels both locally and 
systemically. In addition, longitudinal studies should be performed with a larger sample size including unbiased genotyping of DBP molecule to provide a holistic picture of the impending part of DBP in pathology of periodontitis.

Table 1 Demographic characteristics and full-mouth clinical parameters

\begin{tabular}{|c|c|c|c|c|c|c|c|}
\hline Study group & $\begin{array}{c}\text { Numb } \\
\text { er of } \\
\text { sampl } \\
\text { es }\end{array}$ & $\begin{array}{c}\text { Age } \\
\text { (years) }\end{array}$ & $\begin{array}{l}\text { Gender } \\
\text { (male/ } \\
\text { female) }\end{array}$ & PI & $\begin{array}{l}\text { GI } \\
(\%)\end{array}$ & $\begin{array}{l}\text { PPD } \\
(\mathrm{mm})\end{array}$ & $\begin{array}{l}\text { RAL } \\
(\mathrm{mm})\end{array}$ \\
\hline Group 1(PH) & 20 & $32.1 \pm 2.5$ & $11 / 9$ & $0.3 \pm .1$ & $\begin{array}{c}14.9 \pm \\
3.4\end{array}$ & NA & NA \\
\hline Group 2a (CP) & 20 & $36.4 \pm 3.8$ & $12 / 8$ & $2.5 \pm 0.4$ & $\begin{array}{c}82.0 \pm \\
5.6\end{array}$ & $\begin{array}{c}8.5 \pm \\
1.5\end{array}$ & $\begin{array}{c}11.2 \pm \\
1.7\end{array}$ \\
\hline $\begin{array}{l}\text { Group2b } \\
\text { (ATCP) }\end{array}$ & 20 & $36.4 \pm 3.8$ & $12 / 8$ & $1.2 \pm 0.3$ & $\begin{array}{c}19.1 \pm \\
3.5\end{array}$ & $5.1 \pm 1$ & $7.7 \pm 1.8$ \\
\hline
\end{tabular}

Values are given as $n$ or mean $\pm S D$; $P H$ - Periodontal Health; $C P$ - Chronic periodontitis; ATCP - after treatment Chronic periodontitis; NA - not applicable; PI - plaque index; GI - gingival index; mm - millimeters; $P P D$ - probing pocket depth; $R A L$ - relative attachment loss; $n g / m L$ - nano gram per milliliter

Table 2 Comparison, among study groups, of the mean Vitamin D Binding Protein (DBP) in Gingival Crevicular Fluid (GCF) and Serum

\begin{tabular}{|c|c|c|c|c|c|}
\hline Variable & Comparison group & $\mathrm{N}$ & Mean & $\mathrm{SD}$ & $\begin{array}{l}\mathrm{P}- \\
\text { value }\end{array}$ \\
\hline \multirow{2}{*}{$\begin{array}{l}\text { GCF } \\
(\mathrm{ng} / \\
\mathrm{mL})\end{array}$} & Group $1(\mathrm{PH}) \underline{v s}$ Group 2a $(\mathrm{CP})$ & 20 & $\begin{array}{l}8.5 \\
63 \\
\end{array}$ & $\begin{array}{c}4.9 \\
25.3\end{array}$ & $<0.001^{*}$ \\
\hline & $\begin{array}{l}\text { Group 2a (CP) vs Group 2b } \\
\text { (ATCP) }\end{array}$ & 20 & $\begin{array}{l}63 \\
21\end{array}$ & $\begin{array}{l}25.3 \\
10.4\end{array}$ & $<0.001^{*}$ \\
\hline \multirow{2}{*}{$\begin{array}{c}\text { SERUM } \\
\text { (ng/ } \\
\text { mL) }\end{array}$} & Group $1(\mathrm{PH}) \underline{v s}$ Group 2a (CP) & 20 & $\begin{array}{l}360.2 \\
512.1\end{array}$ & $\begin{array}{l}88.6 \\
72.8\end{array}$ & $<0.001^{*}$ \\
\hline & $\begin{array}{l}\text { Group 2a }(\mathrm{CP}) \text { vs Group } 2 \mathrm{~b} \\
\text { (ATCP) }\end{array}$ & 20 & $\begin{array}{l}512.1 \\
456.9\end{array}$ & $\begin{array}{l}72.8 \\
64.8\end{array}$ & $<0.001^{*}$ \\
\hline
\end{tabular}


${ }^{*} \mathrm{P}<0.05$ significant (Paired sample " $t$ " test)

PH - Periodontal Health; CP - Chronic periodontitis; ATCP - after treatment chronic periodontitis; GCF - Gingival Crevicular Fluid; ng/mL - nano gram per milliliter 
Table 3 Correlation between Gingival Crevicular Fluid (GCF) and Serum in Vitamin D Binding Protein (DBP) with clinical parameters from chronic periodontitis (CP) and after treatment chronic periodontitis group (ATCP)

Variable Comparison group N Correlation P-value

$(\mathrm{r})$

\begin{tabular}{|c|c|c|c|c|}
\hline \multirow{6}{*}{$\mathrm{CP}$} & GCF vs GI & 20 & 0.383 & 0.176 \\
\hline & GCF vs PPD & 20 & -0.223 & 0.444 \\
\hline & GCF vs RAL & 20 & 0.127 & 0.666 \\
\hline & serum vs GI & 20 & 0.406 & 0.149 \\
\hline & serum vs PPD & 20 & -0.494 & 0.073 \\
\hline & serum vs RAL & 20 & -0.023 & 0.939 \\
\hline \multirow{5}{*}{ ATCP } & GCF vs GI & 20 & 0.261 & 0.103 \\
\hline & GCF vs PPD & 20 & -0.339 & 0.236 \\
\hline & GCF vs RAL & 20 & 0.558 & $0.038^{*}$ \\
\hline & serum vs GI & 20 & 0.103 & 0.727 \\
\hline & & 0 & $\begin{array}{c}-0.302 \\
0.343\end{array}$ & $\begin{array}{l}0.293 \\
0.229\end{array}$ \\
\hline
\end{tabular}

PH - Periodontal Health; CP - Chronic periodontitis; ATCP - after treatment Chronic periodontitis; GI - gingival index; mm - millimeters; PPD - probing pocket depth; RAL - relative attachment loss 
Figure 1: Graphic illustration of the flow chart of study inclusion

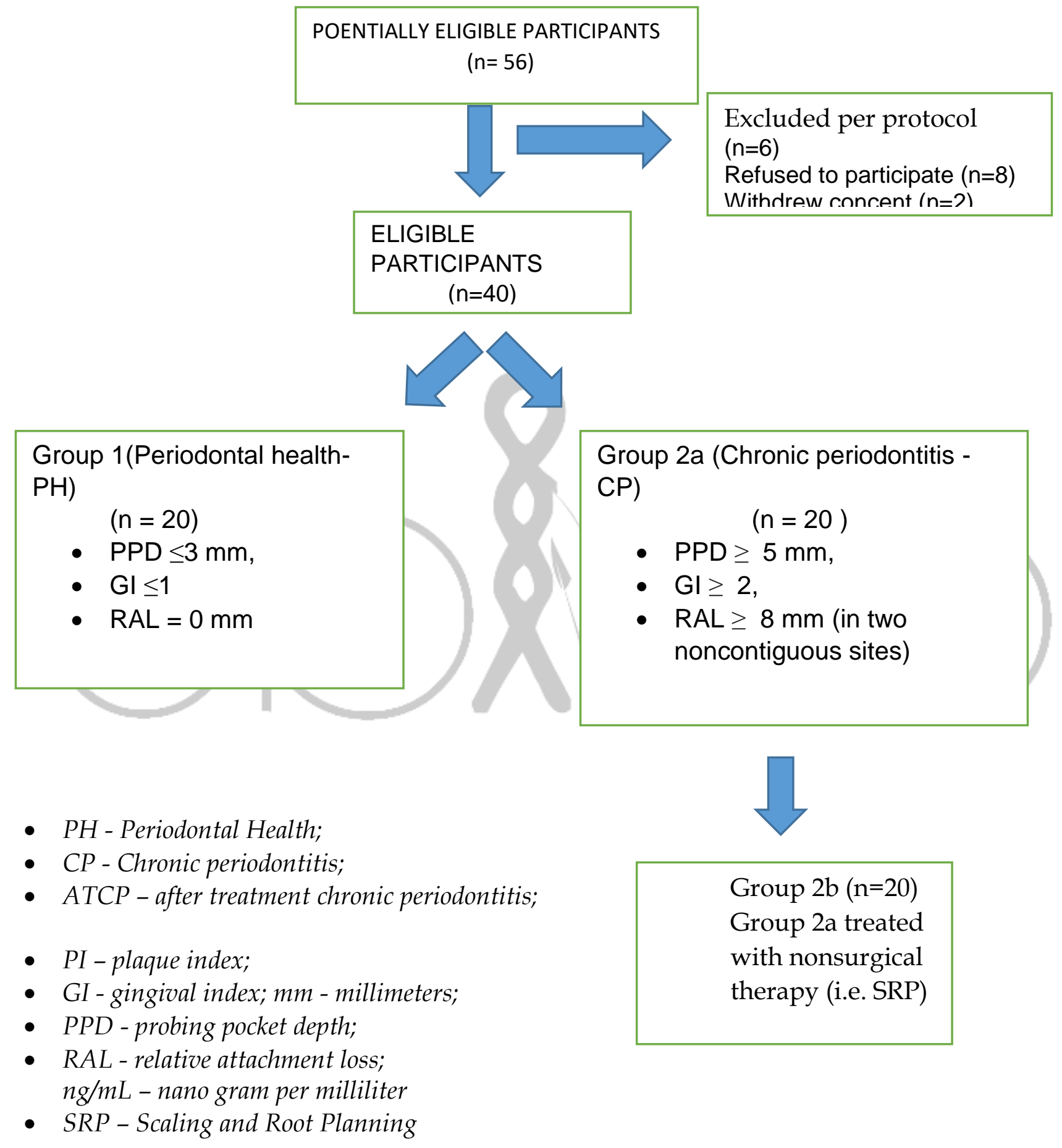




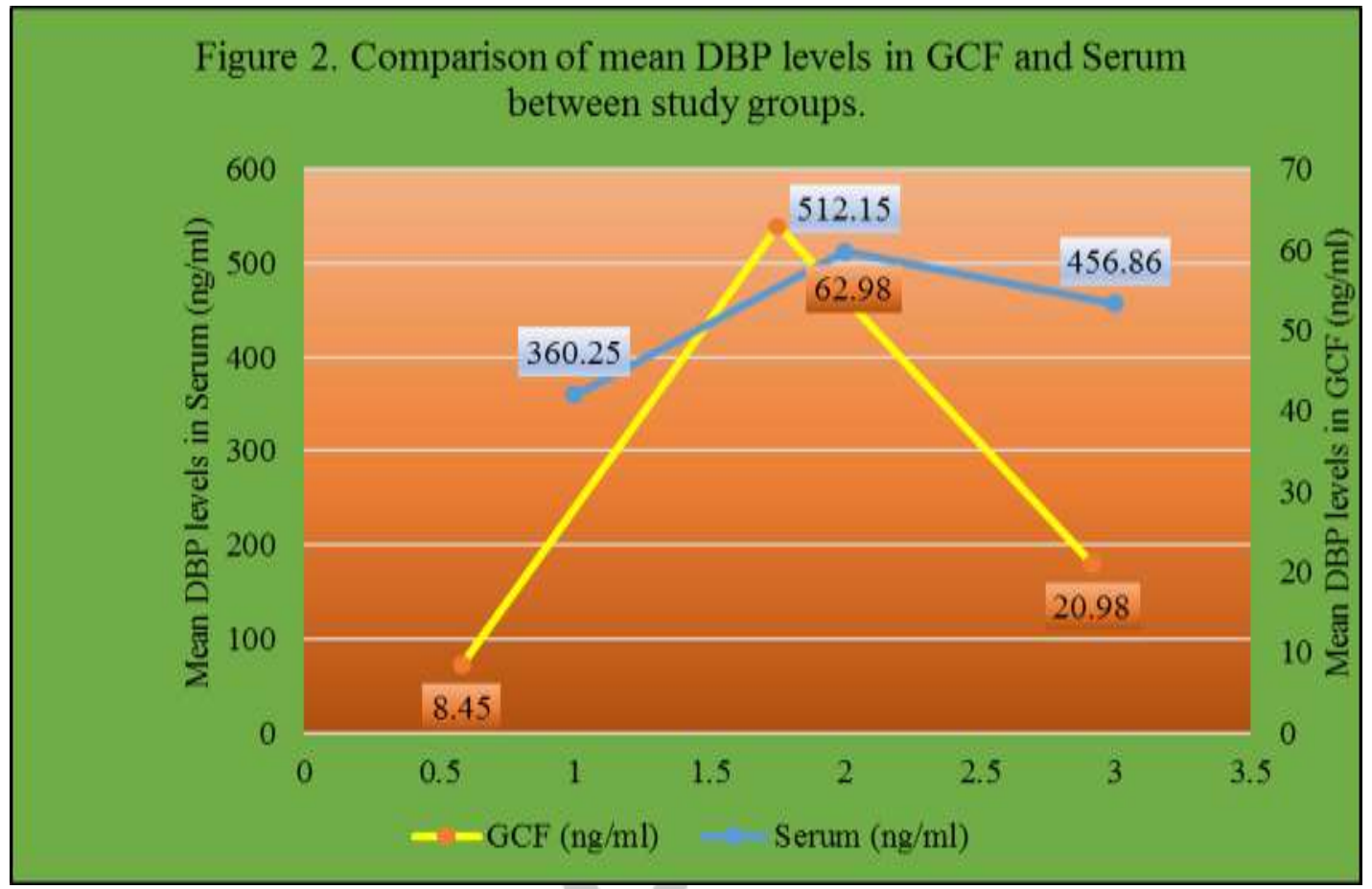

Figure 2: Comparison of mean DBP levels in GCF and Serum between the study groups. GCF Gingival Crevicular Fluid; ng/mL - nano gram per milliliter

\section{CONCLUSION}

Our study shows that DBP concentrations in GCF and serum increased in periodontitis. Furthermore, DBP concentrations amplified with the increasing severity of periodontal condition. Thus, DBP in GCF and serum can be considered as a marker of inflammatory condition in periodontitis. Hence, periodontal disease progression may show a substantial effect in forecasting high-risk people for the most common diseases of the current era like respiratory and cardiovascular diseases etc. Also, periodontal treatment lessens the potential threat of severity of these systemic diseases as it decreases the inflammatory load in systemically compromised and, or else healthy individuals. Further, longitudinal prospective studies involving a larger population are needed to confirm the findings of present study and to better understand the role of DBP in the pathogenesis. Additionally, tending to the clinical implication and pathologic mechanism of DBP in periodontal disease progression is necessary.

\section{ACKNOWLEDGMENT}

The authors wish to thank Dr Palanivel for the statistical analysis support, $\mathrm{Dr}$ Balasubramani and Anburaj Muthumani. 


\section{REFERENCES}

1. Llambés F, Arias-Herrera S, Caffesse

R. Relationship between diabetes and periodontal infection. World journal of diabetes. 2015;6(7):927-35.

2. Genco RJ. Host responses in periodontal diseases: current concepts. J Periodontol. 1992;63(4s):338-55.

3. Speeckaert MM, Wehlou C, Vandewalle S, Taes YE, Robberecht E, Delanghe JR. Vitamin D binding protein, a new nutritional marker in cystic fibrosis patients. Clinical Chemical Laboratory Medicine. 2008;46(3):365-70.

4. Krayer JW, Emerson DL, Goldschmidt-Clermont PJ, Nel AE, Werner PA, Galbraith RM. Qualitative and quantitative studies of Gc (vitamin D-binding protein) in normal subjects and patients with periodontal disease. J Periodontal Res. 1987;22(4):259-63.

5. Guha C, Osawa M, Werner PA, Galbraith RM, Paddock GV. Regulation of human Gc (vitamin d-binding) protein levels: Hormonal and cytokine control of gene expression in vitro. Hepatology. 1995;21 (6):1675-81.

6. Emmett $M$, Miller JL, Crowle AJ. Protein Abnormalities in Adult Respiratory Distress Syndrome, Tuberculosis, and Cystic Fibrosis Sera 1. Proc Soc Exp Biol Med. 1987;184(1):74-82.
7. Blanton D, Han Z, Bierschenk L, LingaReddy MP, Wang $\mathrm{H}$, Clare-Salzler $M$, et al. Reduced Serum Vitamin D-Binding Protein Levels Are Associated With Type 1 Diabetes. Diabetes. $2011 ; 60(10)$ :2566-70.

8. Jeng $L$, Yamshchikov AV, Judd SE, Blumberg HM, Martin GS, Ziegler TR, et al. Alterations in vitamin $D$ status and antimicrobial peptide levels in patients in the intensive care unit with sepsis. J Transl Med. $2009 ; 7(1): 28$.

9. Gasparri C, Curcio A, Torella D, Gaspari M, Celi V, Salituri F, et al. Proteomics reveals high levels of vitamin $D$ binding protein in myocardial infarction. Front Biosci (Elite Ed). 2010;2:796-804.

10. Wilson RT, Bortner JD, Roff A, Das A, Battaglioli EJ, Richie JP, et al. Genetic and environmental influences on plasma vitamin $D$ binding protein concentrations. Translational Research. 2015;165(6):667-76.

11. Bishnoi RJ, Palmer RF, Royall DR. Vitamin $D$ binding protein as a serum biomarker of Alzheimer's disease. J Alzheimers Dis. 2015;43(1):37-45.

12. Zhang $X$, Meng $H, X \cup L$, Zhang $L$, Shi $D$, Feng $X$, et al. Vitamin D-binding protein levels in plasma and gingival crevicular fluid of patients with generalized aggressive periodontitis. Int J Endocrinol. $2014 ; 2014$.

13. WU Y LS GH, Xie YF. Initial comparison of proteomic profiles of whole unstimulated 
saliva obtained from generalized aggressive periodontitis patients and healthy control subjects. J Peridontal Res. 2009;44:636-44.

\section{Zhang $X$, Meng $H$, Sun $X, X \cup L$, Zhang} $L$, Shi $D$, ef al. Elevation of vitamin D-binding protein levels in the plasma of patients with generalized aggressive periodontitis. J Periodontal Res. 2013;48(1):74-9.

15. Armitage GC. Development of a classification system for periodontal diseases and conditions. Ann Periodontol. 1999:4(1):1-6.

16. Baliban RC, Sakellari D, Li Z, DiMaggio PA, Garcia BA, Floudas CA. Novel protein identification methods for biomarker discovery via a proteomic analysis of periodontally healthy and diseased gingival crevicular fluid samples. J Clin Periodontol. 2012;39(3):203-12.

17. Silva-Boghossian CM, Colombo APV, Tanaka M, Rayo C, Xiao Y, Siqueira WL. Quantitative proteomic analysis of gingival crevicular fluid in different periodontal conditions. PLoS One. 2013;8(10):e75898.

18. Li W, Zhu W, Hou J, Meng H. Vitamin D-binding protein expression in healthy tooth and periodontium: an experimental study both in monkeys in vivo and in humans in vitro. J Periodontal Res. 2017.

19. Kew RR, Sibug MA, Liuzzo J, Webster R. Localization and quantitation of the vitamin D binding protein (Gc-globulin) in human neutrophils. Blood. 1993;82(1):27483.

20. Sabbatini A, Petrini $M$, Mattii $L$, Arnaud P, Galbraith R. Vitamin D binding protein is produced by human monocytes. FEBS Lett. 1993;323(1-2):89-92.

21. Kew R, Webster R. Gc-globulin (vitamin D-binding protein) enhances the neutrophil chemotactic activity of $\mathrm{C} 5 \mathrm{a}$ and $\mathrm{C} 5 \mathrm{a}$ des Arg. J Clin Invest. 1988;82(1):364.

22. Schneider $G$, Benis K, Flay N, Ireland $R$, Popoff $S$. Effects of vitamin $D$ binding protein-macrophage activating factor (DBP-MAF) infusion on bone resorption in two osteopetrotic mutations. Bone. 1995; 16(6):657-62.

23. Yamamoto $N$, Naraparaju VR. Vitamin D3-binding protein as a precursor for macrophage activating factor in the inflammation-primed macrophage activation cascade in rats. Cell Immunol. 1996;170(2):161-7.

24. Yamamoto $\mathrm{N}$, Kumashiro R. Conversion of vitamin D3 binding protein (group-specific component) to a macrophage activating factor by the stepwise action of beta-galactosidase of $B$ cells and sialidase of $T$ cells. The Journal of Immunology. 1993;151 (5):2794-802.

25. Ikeda T, Kasai M, Tatsukawa E, Kamitakahara $M$, Shibata $Y$, Yokoi $T$, et al. 
A bone substitute with high affinity for vitamin D-binding protein-relationship with niche of osteoclasts. J Cell Mol Med. 2014;18(1):170-80.

26. DiMartino SJ, Trujillo G, McVoy LA, Zhang J, Kew RR. Upregulation of vitamin D binding protein (Gc-globulin) binding sites during neutrophil activation from a latent reservoir in azurophil granules. Mol Immunol. 2007;44(9):2370-7.

27. Stakisaitis D, Lesauskaitè $V$, Girdauskaitè $M$, Janulionis E, Ulys A, Benetis R. Investigation of Vitamin D-Binding Protein Polymorphism Impact on Coronary Artery Disease and Relationship with Longevity: Own Data and a Review. Int J Endocrinol. 2016;2016.
28. Dimeloe S, Hawrylowicz C. A direct role for vitamin D-binding protein in the pathogenesis of COPD? 2011.

29. Schellenberg D, Pare PD, Weir TD, Spinelli JJ, Walker BA, Sandford AJ. Vitamin $D$ binding protein variants and the risk of COPD. Am J Respir Crit Care Med. 1998;157(3):957-61.

30. Powe $\mathrm{CE}$, Ricciardi $\mathrm{C}$, Berg $\mathrm{AH}$, Erdenesanaa D, Collerone G, Ankers E, et al. Vitamin D-binding protein modifies the vitamin D-bone mineral density relationship. J Bone Miner Res. 2011;26(7):1609-16. 